\title{
PEMBUATAN PROSEDUR MANAJEMEN INSIDEN BERDASARKAN ITIL V3 DAN COBIT 5 PADA RUMAH SAKIT PHC SURABAYA
}

\author{
Ahmad Holil Noor Ali ${ }^{1)}$, Mohammad Hafid Ichsani ${ }^{2)}$, Hery Setiawan ${ }^{3)}$ \\ Jurusan Sistem Informasi, Fakultas Teknologi Informasi, Institut Teknologi Sepuluh \\ Nopember (ITS) \\ Jl. Arief Rahman Hakim, Surabaya 60111 Indonesia \\ e-mail: aholil@ymail.com ${ }^{1)}$ hafid.ichsani@gmail.com ${ }^{2)}$, hery.nugroho@gmail.com ${ }^{3)}$
}

\begin{abstract}
PHC hospital Surabaya use information technology as a supporter to the provider of the services provided and make the management information System unit with one of its function to ensures data availability and information either medic and non-medical.. The incidents handling so far only as handling reactively without any grooves and good documentation. So, incident management procedures need to be made in order for better incident handling incidents and in accordance with the existing resource, its also can eventually guarantee the availability of it services and minimize the impact of the incident. The steps in creating procedures is, (1) the preparation of the study,, (2) analyze the information, (3) the making of incident management procedure, (4) and then carried out procedure verification and procedures validation. The results of this research is the form of eleven incident management procedures based on ITIL v3 for PHC Hospital Surabaya which have been verified against the COBIT 5 's controls and has performed validation using simulation with BPMN notation..

\section{Abstrak}

Rumah Sakit PHC Surabaya menjadikan Teknologi Informasi sebagai pendukung hingga penyedia layanan yang diberikan dan membentuk unit Sistem Informasi Manajemen dengan salah satu tugasnya menjamin ketersediaan data dan informasi baik medik maupun non-medik. Penanganan insiden selama ini hanya sebatas penanganan secara reaktif tanpa ada alur dan dokumentasi yang baik. Untuk itu perlu dibuat prosedur manajemen insiden agar penanganan insiden dapat berjalan baik dan sesuai dengan resource yang ada sehingga pada akhirnya dapat menjamin ketersediaan layanan TI dan meminimalkan dampak dari insiden. Langkah-langkah dalam pembuatan prosedur tersebut yaitu (1) persiapan, (2) analisa informasi, (3) pembuatan prosedur manajemen insiden, (4) kemudian dilakukan verifikasi prosedur dan validasi prosedur. Hasil dari penilitian ini berupa sebelas prosedur manajemen insiden TI berdasarkan ITIL v3 untuk RS PHC Surabaya yang telah dilakukan verifikasi terhadap control COBIT 5 dan telah dilakukan validasi menggunakan simulasi dengan notasi BPMN.
\end{abstract}

Kata kunci: prosedur, manajemen insiden, ITIL, tata kelola TI, manajemen layanan TI

\section{PENDAHULUAN}

Rumah Sakit PHC Surabaya merupakan rumah sakit swasta sebagai anak perusahaan PT. Pelayaran Indonesia yang selalu memberikan pelayanan kesehatan secara cepat, akurat, mudah, dan efektif. Tahun 2012 Rumah Sakit PHC Surabaya mendapatkan sertifikasi ISO 9001 manajemen mutu untuk pelayanan rawat inap dan laboratorium. Saat ini RS PHC Surabaya telah menjadikan Teknologi Informasi sebagai pendukung hingga penyedia dari layanan kesehatan yang diberikan seperti layanan rawat inap, rawat jalan, dan rekam medik. Terkait dengan hal tersebut, maka dibentuk unit Sistem Informasi Manajemen dengan salah satu tugasnya yaitu bertanggung jawab dan menjamin ketersediaan data dan informasi. Jaminan ketersediaan layanan menjadi hal yang penting mengingat layanan teknologi informasi tidak luput dari insiden yang dapat menyebabkan

\section{gangguan.}

Pengelolaan insiden sendiri memiliki peran besar pada RS PHC Surabaya karena semakin banyaknya sumber daya TI yang dikelola dan banyaknya proses bisnis yang terkait dengan dukungan TI sehingga jika terjadi insiden maka akan sangat mengganggu layanan yang diberikan. Insiden TI yang sering terjadi pada RS PHC Surabaya selama ini adalah kesalahan perangkat keras seperti pc mati, gangguan jaringan, gangguan printer serta gangguan perangkat lunak seperti kesalahan entri pada aplikasi rawat inap dan rawat jalan, gangguan integrasi antar aplikasi, dan bug pada aplikasi/SI yang dikembangkan. Penanganan insideninsiden tersebut ditangani oleh para staf TI yang terbatas tanpa ada panduan seperti kebijakan dan prosedur yang jelas sehingga membutuhkan waktu yang lama dan saling tumpang tindih. 
Penanganan dan pengelolaan insiden yang tepat sangat diperlukan untuk memastikan bahwa layanan TI tetap tersedia dan mendukung pelayanan kesehatan lebih efektif.

Kesalahan umum yang banyak terjadi ketika mengembangkan layanan adalah fokus pada menanggapi insiden, bukan pada mencegah masalah terjadi dari awal (itSMF International, 2007). Hubungan antara aktivitas layanan tersebut belum difahami dengan baik sehingga banyak organisasi kurang efektif atau bahkan gagal dalam melakukan pencegahan masalah secara proaktif.

Berdasarkan ITSM, suatu insiden idealnya tidak hanya ditanggapi tetapi juga harus dikelola. Pengelolaan insiden tersebut tidak hanya sebatas pada bagaimana suatu insiden tersebut ditanggapi, melainkan bagaimana suatu insiden dikelola secara proaktif agar tidak menimbulkan dampak lain yang lebih parah (Addy, 2007).

Penelitian ini bertujuan untuk menyusun prosedur manajemen insiden sehingga pengelolaan insiden semakin baik dan meminimalkan ketergantungan pada orang tertentu dan pemerataan fungsi peran dan tanggungjawab. Penelitian ini menghasilkan dokumen prosedur manajemen insiden yang terdiri dari tujuan, indikator, ruang lingkup, rincian aktivitas, diagram RACI, diagram alur prosedur yang menggunakan notasi BPMN, serta formulir dan template pendukung.

Prosedur sendiri merupakan suatu cara untuk melaksanakan suatu kegiatan atau proses yang dapat didokumentasikan atau tidak (BSNI, 2008), dan dalam kaitannya dengan tata kelola perusahaan, prosedur merupakan suatu perangkat yang digunakan untuk menerapkan strategi perusahaan. Prosedur juga dapat diartikan sebagai suatu statemen spesifik yang didesain untuk menyediakan arahan dalam tindakan-tindakan yang diperlukan untuk mendukung kebijakan organisasi (Wallace \& Webber, 2014). Tujuan dari adanya prosedur adalah untuk menjelaskan bagaimana suatu hal/aktivitas diselesaikan. Prosedur memiliki beberapa karakteristik menurut Wallace dan Webber yaitu memiliki pengaplikasian yang terbatas, mudah untuk berubah sebagai system baru yang lebih operasional, mendeskripsikan proses, serta prosedur secara umum sangat detail.

ITIL mendefinisikan insiden sebagai suatu kejadian apapun yang bukan bagian atau diluar standar operasional layanan yang dapat menyebabkan gangguan pada layanan TI atau penurunan kualitas dari layanan TI. Manajemen insiden merupakan proses yang berhadapan dengan insiden dan merupakan jalur utama pada pelaporan terkait permasalahan. Perilaku yang jarang dan tidak dapat diprediksi dari kontak end user menjadikan hubungan yang efektif dan terpercaya sulit untuk disatukan (Addy, 2007). Fungsi manajemen insiden yang secara umum berada pada service atau service desk menjadikan perannya sangat mendukung dalam ruang manajemen layanan TI yaitu untuk mengatasi/memperbaiki insiden yang muncul berdasarkan user secepat mungkin. Manajemen insiden sendiri juga memiliki suatu kerangka aktivitas.

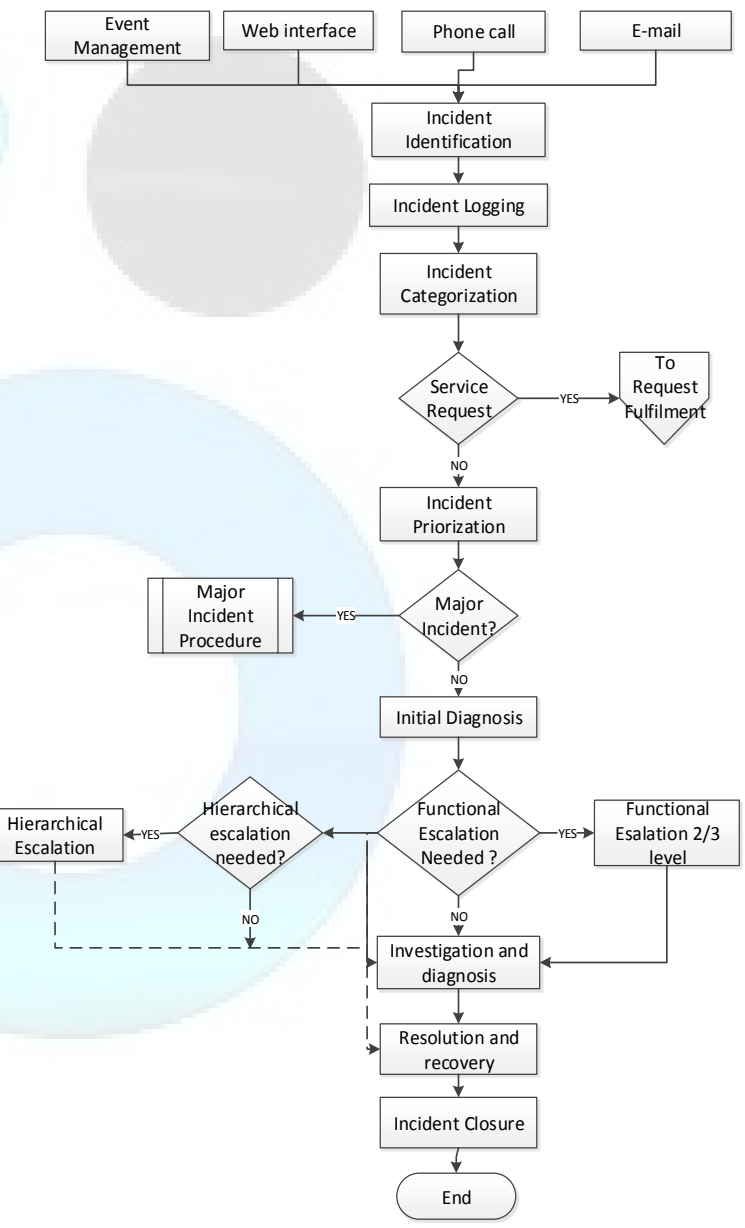

Gambar 2. Proses Manajemen Insiden ITIL

Tujuan utama dari proses manajemen insiden adalah memulihkan operasional layanan secara normal secepat mungkin dan meminimalkan dampak pada operasional bisnis (ITILv3, 2011). Operasional layanan secara normal dalam hal ini didefinisikan sesuai pada operasional layanan dengan batasan Service Level Agreement (SLA).

Prosedur juga memiliki kaitan yang sangat denga tata kelola TI yang dalam prakteknya terdapat best practice sebagai pedoman dan acuan untuk melaksanakan tata kelola TI yang baik. Penulis menggunakan COBIT 5 sebagai pendukung pembuatan prosedur manajemen insiden, yaitu 
pada proses Manage Service Request and Incident yang merupakan salah satu proses yang ada pada domain proses Deliver, Service, and Support yang fokus pada dukungan layanan TI. Proses Manage Service Request and Incident menyediakan respon yang tepat waktu dan efektif pada permintaan user dan penyelesaian solusi dari segala jenis insiden, selain itu juga melakukan pemulihan layanan secara normal, mencatat request dari user, melakukan investigasi, diagnosa, eskalasi, dan mengatasi insiden (ISACA, 2012).

Prosedur manajemen insiden yang dibuat merupakan suatu dokumentasi dari urutan aktivitas yang digunakan dalam melakukan manajemen insiden. Urutan aktivitas terebut digambarkan ke dalam suatu diagram proses bisnis dari sub aktivitas manajemen insiden yang menggunakan standar notasi Business Process Model and Notation (BPMN). BPMN merupakan sebuah standar untuk pemodelan proses bisnis yang menyediakan notasi grafis untuk menspesifikkan proses bisnis ke dalam suatu diagram proses bisnis. Tujuan utama dari BPMN adalah untuk menyediakan standar notasi yang siap untuk dipahami untuk semua stakeholder bisnis. Stakeholder tersebut termasuk business analys yang membuat dan memperbaiki proses, developer yang bertanggungjawab untuk mengimplementasikan proses, dan business manager yang memantau dan mengelola proses tersebut (Simpson, 2004). BPMN terbatas pada dukungan konsep pemodelan yang dapat diterapkan kedalam proses bisnis. Pemodelan lain pada organisasi untuk tujuan bukan proses merupakan area diluar ruang lingkup dari BPMN. Beberapa contoh pemodelah dalam BPMN antara lain struktur organisasi, breakdown fungsional. dan data model.

BPMN memiliki empat kategori elemen dasar yaitu event, activity, gateway, dan connection. (Bizagi, 2014). Event digambarkan dengan lingkaran dan menunjukkan sesuatu yang terjadi yang terdiri dari start event untuk memulai proses, intermediate event untuk jeda, dan end event untuk mengakhiri proses.

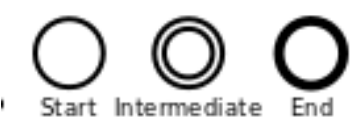

Gambar 1 Notasi event

Sebuah activity digambarkan dengan persegi panjang dengan sisi lengkung yang mendeskripsikan suatu pekerjaan atau aktivitas yang harus diselesaikan.

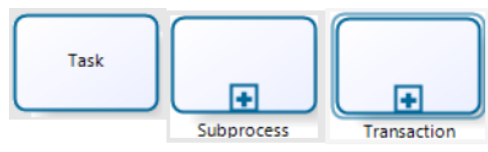

Gambar 2 Notasi activity

Sedangkan untuk gateway digambarkan dengan bentuk belah ketupat dan digunakan untuk menentukan pemisahan dan penggabungan dari suatu jalur yang tergantung pada kondisi.

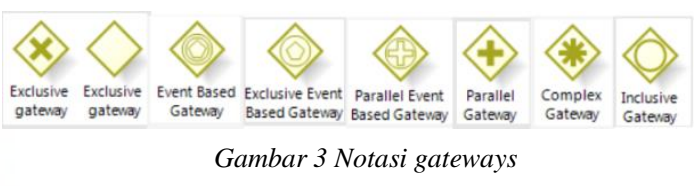

Objek-objek pada diagram dihubungkan satu sama lain menggunakan connection object. Connection obejc terdiri dari 3 tipe yaitu :

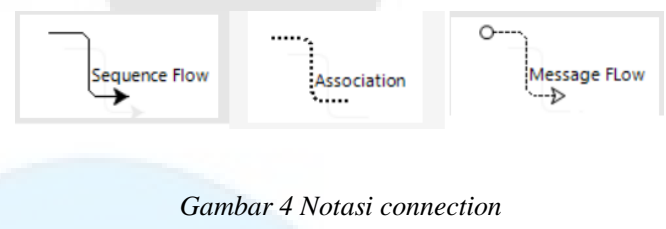

\section{METODE PENELITIAN}

Penelitian ini didasarkan pada empat tahapan yaitu:

1. Persiapan

2. Analisa Informasi

3. Pembuatan prosedur manajemen insiden

4. Verifikasi dan validasi prosedur

Untuk lebih jelasnya, tahapan penelitian ini dapat dilihat pada gambar 6 .

\section{HASIL DAN PEMBAHASAN}

Hasil yang diperoleh dalam pembuatan prosedur manajemen insiden untuk RS Surabaya akan dibahas pada bagian ini.

\subsection{Manajemen Insiden helpdesk RS PHC Surabaya}

RS PHC Surabaya melaksanakan proses manajemen insiden sebagai upaya untuk memastikan bahwa layanan teknologi informasi tetap tersedia dan berjalan dengan semestinya. Untuk mencapai hal tersebut, dibentuklah Helpdesk yang sekaligus menjadi IT support pada RS PHC Surabaya. Proses manajemen insiden pada RS PHC Surabaya belum memiliki prosedur yang jelas dan terdokumentasi. 


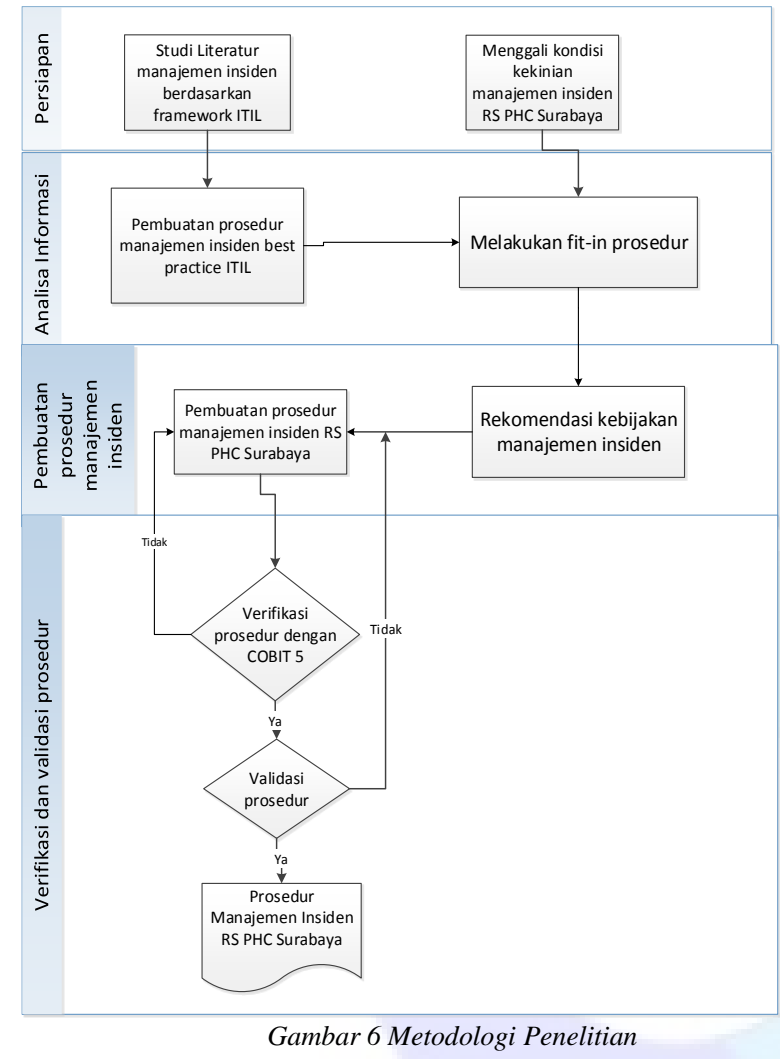

Penanganan insiden menggunakan aplikasi helpdesk yang berfungsi sebagai channel pelaporan dan pencatatan insiden yang terjadi. Ketika insiden terjadi, pengguna yang mengalami insiden akan melaporkan keluhannya melalui aplikasi helpdesk yang kemudian dicatat dengan diberikan nomor urut dan status penanganan. Notifikasi insiden baru muncul pada semua level penanganna dan fungsi yang bertanggungjawab dengan insiden yang muncul akan mengambil alih penanganan. Insiden yang baru masuk dan belum direspon memiliki status "Baru" dengan warna merah, insiden yang dalam penanganan memiliki status "Proses" dengan warna kuning, dan insiden yang telah selesai ditangani memiliki status "OK" dengan warna hijau.

Prosedur yang dibuat didasarkan pada framework manajemen insiden ITIL yang masih umum. Agar dapat diterapkan pada RS PHC Surabaya, prosedur tersebut perlu dilakukan fitin atau penyesuaian. Fit-in yang dilakukan pada prosedur manajemen insiden yang dibuat untuk RS PHC Surabaya adalah dijelaskan berikut ini.

\subsection{Fit-in prosedur manajemen insiden}

Prosedur yang dibuat didasarkan pada framework manajemen insiden ITIL yang masih umum. Agar dapat diterapkan pada RS PHC Surabaya, prosedur tersebut perlu dilakukan fitin atau penyesuaian. Fit-in yang dilakukan pada prosedur manajemen insiden yang dibuat untuk
RS PHC Surabaya adalah:

Tabel 1 Fit-in yang dilakukan terhadap prosedur

\begin{tabular}{|c|c|}
\hline $\begin{array}{l}\text { Prosedur } \\
\text { manajemen } \\
\text { insiden }\end{array}$ & Penyesuaian \\
\hline $\begin{array}{l}\text { Identifikasi } \\
\text { Insiden }\end{array}$ & $\begin{array}{l}\text { Perubahan peran level } 1 \\
\text { menjadi Helpdesk Operator } \\
(\mathrm{HO})\end{array}$ \\
\hline $\begin{array}{l}\text { Pencatatan } \\
\text { Insiden }\end{array}$ & 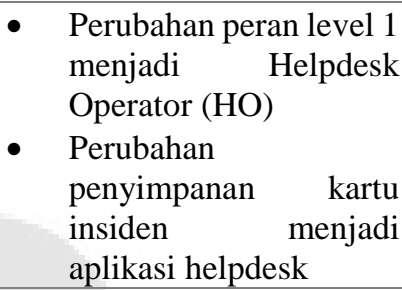 \\
\hline $\begin{array}{l}\text { Kategorisasi } \\
\text { Insiden }\end{array}$ & $\begin{array}{l}\text { Perubahan peran level } 1 \\
\text { menjadi Helpdesk Operator } \\
(\mathrm{HO})\end{array}$ \\
\hline $\begin{array}{l}\text { Prioritisasi } \\
\text { Insiden }\end{array}$ & $\begin{array}{l}\text { Perubahan peran level } 1 \\
\text { menjadi Helpdesk Operator } \\
(\mathrm{HO})\end{array}$ \\
\hline $\begin{array}{l}\text { Diagnosa Awal } \\
\text { Insiden }\end{array}$ & $\begin{array}{l}\text { Perubahan peran level } 1 \\
\text { menjadi Helpdesk Operator } \\
(\mathrm{HO})\end{array}$ \\
\hline $\begin{array}{l}\text { Eskalasi } \\
\text { Insiden }\end{array}$ & $\begin{array}{ll}\text { - } & \text { Perubahan peran level } 1 \\
\text { menjadi Helpdesk } \\
\text { Operator (HO) } \\
\text { - } \\
\text { Perubahan peran level } 2 \\
\text { menjadi Helpdesk } \\
\text { Specialist }\end{array}$ \\
\hline $\begin{array}{l}\text { Investigasi dan } \\
\text { Diagnosa } \\
\text { Insiden }\end{array}$ & \begin{tabular}{ll} 
- & \multicolumn{2}{l}{ Perubahan peran level 1 } \\
menjadi Helpdesk \\
Operator (HO) \\
- & Perubahan peran level 2 \\
menjadi & Helpdesk \\
& Specialist \\
- & Mendetilkan dukungan \\
level 2 fungsional \\
menjadi $\quad$ Software \\
manager, network \\
manager, maintenance \\
manager, dan data \\
management manager
\end{tabular} \\
\hline $\begin{array}{l}\text { Resolusi } \\
\text { Insiden }\end{array}$ & $\begin{array}{l}\text { Perubahan peran level } 1 \\
\text { menjadi Helpdesk Operator } \\
(\mathrm{HO})\end{array}$ \\
\hline $\begin{array}{l}\text { Penutupan } \\
\text { Insiden }\end{array}$ & $\begin{array}{l}\text { Perubahan peran level } 1 \\
\text { menjadi Helpdesk Operator } \\
(\mathrm{HO})\end{array}$ \\
\hline
\end{tabular}

\subsection{Prosedur manajemen insiden}

Prosedur manajemen insiden yang dihasilkan untuk RS PHC Surabaya merupakan prosedur yang didasarkan pada manajemen insiden ITIL yang telah dilakukan penyesuaian. Peran fungsi dalam melaksanakan manajamen insiden yang digunakan antara lain: 
Jurnal Sistem Informasi, Volume 5, Nomor 4, September 2015, 462-469

Tabel 1 Fungsi pelaksana manajemen insiden:

\begin{tabular}{ll}
\hline \multicolumn{1}{c}{ Role ITIL } & \multicolumn{1}{c}{$\begin{array}{c}\text { Role RS PHC } \\
\text { Surabaya }\end{array}$} \\
\hline User & Pengguna/pelapor \\
\hline Incident Manager & $\begin{array}{l}\text { Manajer Teknologi } \\
\text { Informasi }\end{array}$ \\
\hline Level 1 Support & \\
\hline Helpdesk Operator & Helpdesk Operator \\
\hline Level 2 Support & Kepala \\
\hline Helpdesk & $\begin{array}{l}\text { Teknologi } \\
\text { Specialist }\end{array}$ \\
& $\begin{array}{l}\text { Informasi/Kepala } \\
\text { Bagian }\end{array}$ \\
& Manajemen Sistem \\
\hline Level 2 Fungsional & \\
\hline Software Manager & PJ Perangkat Lunak \\
\hline Maintenance & PJ Perangkat Keras \\
Manager & \\
\hline Network Manager & PJ Perangkat Keras \\
\hline Data Management & PJ Manajemen Data \\
Manager & \\
\hline
\end{tabular}

\subsection{Helpdesk RS PHC Surabaya}

Untuk mengatur aktivitas manajemen insiden agar sesuai dengan tujuan, maka juga dibuat rekomendasi kebijakan manajemen insiden (Silitonga \& Ali, 2010). Rekomendasi kebijakan yang dibuat merupakan bentuk usulan untuk organisasi ketika akan menerapkan prosedur secara utuh. Rekomendasi kebijakan yang diberikan meliputi:

Tabel 2 Rekomendasi kebijakan manajemen insiden

\begin{tabular}{|c|c|}
\hline Kebijakan & Deskripsi \\
\hline $\begin{array}{l}\text { - Kebijakan fungsi } \\
\text { penanggungjawab } \\
\text { penanganan insiden }\end{array}$ & $\begin{array}{l}\text { Mengatur mengenai } \\
\text { fungsi } \\
\text { penanggungjawab } \\
\text { dalam melaksanakan } \\
\text { penanganan untuk } \\
\text { insiden yang sesuai. }\end{array}$ \\
\hline $\begin{array}{l}\text { - Kebijakan } \\
\text { pencatatan insiden }\end{array}$ & $\begin{array}{lr}\text { Mengatur } & \text { mengenai } \\
\text { kebutuhan } & \text { dan } \\
\text { deskripsi } & \text { detil } \\
\text { informasi } & \text { untuk } \\
\text { dilakukan pencatatan }\end{array}$ \\
\hline $\begin{array}{l}\text { - Kebijakan } \\
\text { kategorisasi insiden }\end{array}$ & $\begin{array}{l}\text { Memberikan } \\
\text { panduan mengenai } \\
\text { penentuan kategori } \\
\text { dari insiden }\end{array}$ \\
\hline $\begin{array}{l}\text { - Kebijakan } \\
\text { prioritisasi Insiden }\end{array}$ & $\begin{array}{l}\text { Memberikan } \\
\text { panduan dalam } \\
\text { melakukan peniliain } \\
\text { dampak, } \\
\text { kepentingan, dan } \\
\text { prioritisasi insiden }\end{array}$ \\
\hline $\begin{array}{l}\text { - Kebijakan } \\
\text { penanganan insiden }\end{array}$ & $\begin{array}{l}\text { Memberikan } \\
\text { panduan mengenai } \\
\text { standar target waktu }\end{array}$ \\
\hline
\end{tabular}

\begin{tabular}{llr}
\hline Kebijakan & Deskripsi \\
\hline & dalam menangani \\
& insiden & sesuai \\
& dengan & priroritas.
\end{tabular}

Proses fit-in kemudian menghasilkan dokumen prosedur yang terdiri dari sebelas proses dalam menangani insiden. Prosedur tersebut terdiri dari tujuan, ruang lingkup, indikator, rincian aktivitas, diagram RACI, diagram alur yang menggunakan notasi BPMN, serta formulir dan template pendukung. Sebelas prosedur tersebut antara lain :

Tabel 4 Prosedur Manajemen Insiden RS PHC Surabaya

\begin{tabular}{|c|c|}
\hline Prosedur & Tujuan \\
\hline $\begin{array}{l}\text { Identifikasi } \\
\text { Insiden }\end{array}$ & $\begin{array}{l}\text { 1. Memastikan bahwa setiap } \\
\text { insiden dapat diidentifikasi } \\
\text { sebelum menimbulkan } \\
\text { dampak negatif yang lebih } \\
\text { parah pada proses bisnis } \\
\text { yang sedang berlangsung } \\
\text { 2. Memastikan bahwa kartu } \\
\text { insiden dengan status } \\
\text { "belum selesai" atau } \\
\text { "dalam proses" dibuka } \\
\text { kembali } \\
\text { didistribusikan }\end{array}$ \\
\hline $\begin{array}{l}\text { Pencatatan } \\
\text { Insiden }\end{array}$ & $\begin{array}{l}\text { 1. Memastikan bahwa insiden } \\
\text { yang terjadi dicatat sebagai } \\
\text { dasar informasi pelaksanaan } \\
\text { proses penanganan insiden } \\
\text { 2. Memastikan bahwa } \\
\text { informasi yang relevan } \\
\text { terkait insiden telah dicatat } \\
\text { secara lengkap dan } \\
\text { melakukan verifikasi } \\
\text { kepada sumber. } \\
\text { 3emastikan bahwa terdapat } \\
\text { ringkasan insiden dan kata } \\
\text { kunci pencarian kartu } \\
\text { insiden }\end{array}$ \\
\hline $\begin{array}{l}\text { Kategorisasi } \\
\text { Insiden }\end{array}$ & $\begin{array}{l}\text { untuk memastikan bahwa } \\
\text { dilakukan kategorisasi insiden } \\
\text { secara tepat dan dalam waktu } \\
\text { yang singkat. }\end{array}$ \\
\hline $\begin{array}{l}\text { Prioritisasi } \\
\text { Insiden }\end{array}$ & $\begin{array}{l}\text { 1. untuk memastikan bahwa } \\
\text { laporan insiden yang masuk } \\
\text { mendapatkan prioritas yang } \\
\text { sesuai untuk ditangani } \\
\text { 2. Memastikan bahwa } \\
\text { penugasan penanganan } \\
\text { insiden diberikan pada staf } \\
\text { yang tepat }\end{array}$ \\
\hline $\begin{array}{c}\text { Diagnosa } \\
\text { Awal Insiden }\end{array}$ & $\begin{array}{l}\text { 1. untuk memastikan bahwa } \\
\text { tindakan diagnosa awal } \\
\text { dilakukan oleh operator } \\
\text { helpdesk dalam waktu yang } \\
\text { singkat }\end{array}$ \\
\hline
\end{tabular}




\begin{tabular}{|c|c|}
\hline Prosedur & Tujuan \\
\hline & $\begin{array}{l}\text { 2. } \begin{array}{l}\text { Memastikan } \\
\text { kepentingan } \\
\text { mendapatkan pasien } \\
\text { penanganan yang sesuai }\end{array} \\
\text { 3. } \begin{array}{l}\text { Memastikan } \\
\text { diagnosa yang dilakukan }\end{array} \\
\text { dapat memberikan masukan } \\
\text { bagi penanganan insiden } \\
\text { secara keseluruhan dan } \\
\text { memungkinkan untuk } \\
\text { memberikan solusi dari } \\
\text { insiden }\end{array}$ \\
\hline $\begin{array}{l}\text { Eskalasi } \\
\text { Insiden }\end{array}$ & $\begin{array}{l}\text { 1. Untuk memastikan } \\
\text { dilakukannya } \\
\text { eskalasi dalam waktu } \\
\text { singkat untuk memenuhi } \\
\text { target waktu penanganan } \\
\text { sesuai SLA. } \\
\text { 2. memastikan } \\
\text { dilakukan eskalasi } \\
\text { pertimbangan atas tindakan } \\
\text { penanganan yang sudah } \\
\text { dilakukan } \\
\text { 3. Memastikan } \\
\text { dilakukan pahwa } \\
\text { penanggungjawab } \\
\text { penanganan insiden setelah } \\
\text { eskalasi }\end{array}$ \\
\hline \multirow[t]{3}{*}{$\begin{array}{l}\text { Investigasi } \\
\text { dan Diagnosa } \\
\text { Insiden }\end{array}$} & $\begin{array}{l}\text { 1. Untuk memastikan } \\
\text { dilakukannya investigasi } \\
\text { secara menyeluruh dan } \\
\text { mendalam untuk } \\
\text { menemukan sumber } \\
\text { permasalahan insiden }\end{array}$ \\
\hline & $\begin{array}{l}\text { 2. Memastikan } \\
\begin{array}{l}\text { investigasi } \\
\text { dilakukan }\end{array} \text { dantivitas } \\
\text { standar }\end{array}$ \\
\hline & $\begin{array}{llr}\text { 3. Memastikan bahwa } & \text { solusi } \\
\text { yang ditemukan } & \text { sesuai } \\
\text { dengan insiden } & \text { yang } \\
\text { dimaksud } & & \\
\end{array}$ \\
\hline $\begin{array}{l}\text { Resolusi } \\
\text { Insiden }\end{array}$ & $\begin{array}{l}\text { memastikan bahwa solusi atas } \\
\text { insiden telah teruji dan dapat } \\
\text { diimplementasikan. }\end{array}$ \\
\hline $\begin{array}{l}\text { Penutupan } \\
\text { Insiden }\end{array}$ & $\begin{array}{l}\text { 1. Memastikan } \begin{array}{l}\text { bahwa } \\
\text { dilakukan aktivitas } \\
\text { penutupan insiden }\end{array} \\
\text { 2. Memastikan bahwa keluhan } \\
\text { dari User diterima }\end{array}$ \\
\hline $\begin{array}{l}\text { Pelaporan } \\
\text { Insiden }\end{array}$ & $\begin{array}{l}\text { 1. Untuk memastikan bahwa } \\
\text { dilakukannya rekap harian } \\
\text { laporan insiden } \\
\text { 2. Memastikan bahwa } \\
\text { dilakukannya rekap bulanan } \\
\text { laporan insiden } \\
\text { 3. Memastikan bahwa laporan } \\
\text { penanganan insiden } \\
\text { digunakan sebagai bahan }\end{array}$ \\
\hline
\end{tabular}

\begin{tabular}{cl}
\hline Prosedur & \multicolumn{1}{c}{ Tujuan } \\
\hline & $\begin{array}{l}\text { evalusai penaganganan } \\
\text { selanjutnya }\end{array}$ \\
\hline $\begin{array}{c}\text { Evaluasi } \\
\text { penanganan } \\
\text { Insiden }\end{array}$ & $\begin{array}{l}\text { Untuk memastikan bahwa } \\
\text { evaluasi dilakukan setiap } \\
\text { bulan untuk meningkatkan } \\
\text { kualitas penanganan insiden } \\
\end{array}$ \\
2. Memastikan bahwa hasil \\
evaluasi ditindaklanjuti oleh \\
masing-masing level \\
penanganan insiden
\end{tabular}

Diagram alur yang digunakan dalam prosedur menggunakan notasi BPMN yang menggambarkan aliran aktivitas dari prosedur yang dibuat.
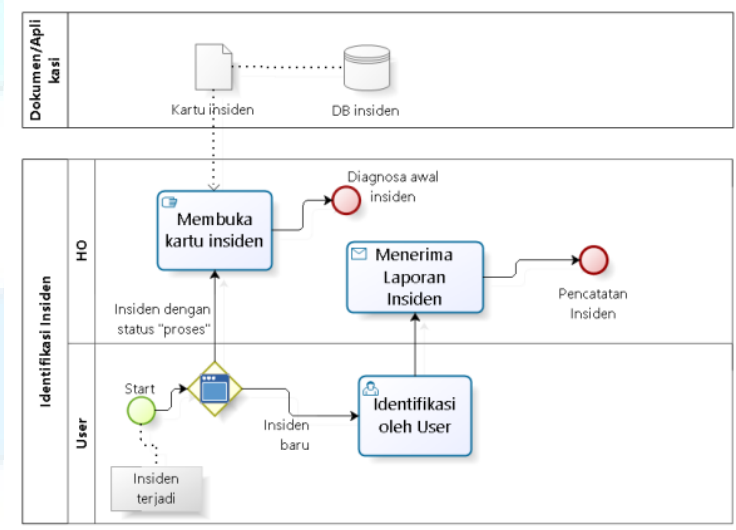

Gambar 7. Flowchart Prosedur

Secara garis besar, prosedur yang dibuat terdiri dari hierarki mulai dari kebijakan, prosedur, hingga formulir yang digunakan, seperti yang ditunjukkan pada gambar 8 . 


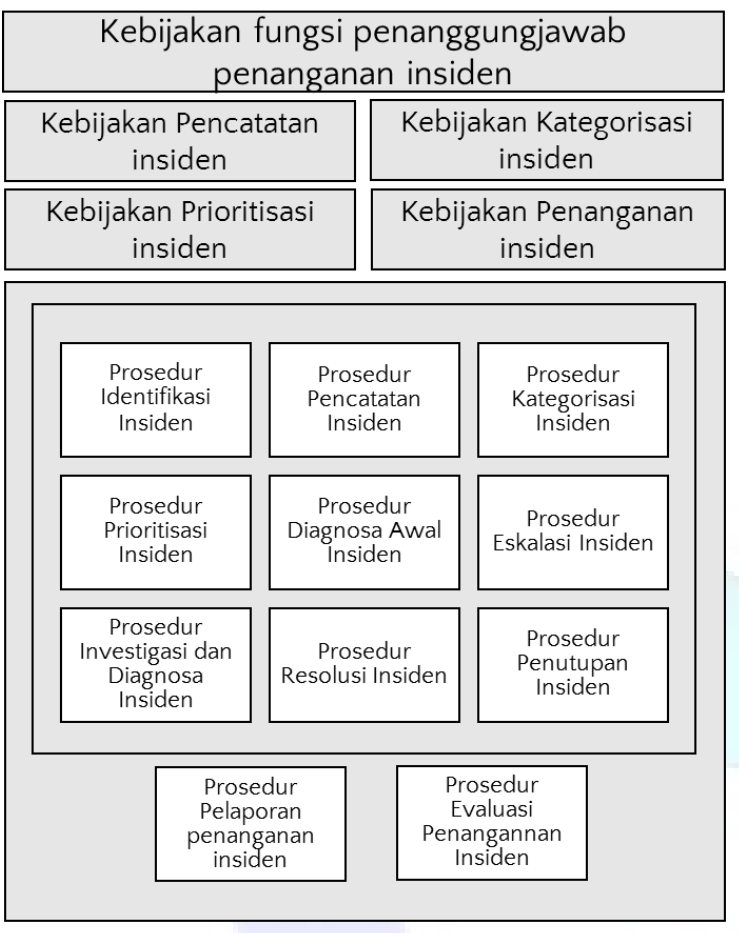

Formulir dan Template pendukung

Gambar 8. Struktur prosedur manajemen insiden RS PHC Surabaya

Kebijakan digunakan sebagai suatu perangkat yang mengatur segala ketentuan dalam melaksanakan prosedur manajemen insiden, kemudian prosedur yang dibuat terdiri dari sebelas prosedur dimana Sembilan prosedur yang berasal dari ITIL merupakan aktivitas yang berkelanjutan sedangkan dua prosedur tambahan merupakan aktivitas yang dilakukan dalam periode waktu tertentu. Formulir dan template juga digunakan sebagai pendukung dalam melaksanakan aktivitas manajemen insiden.

\subsection{Verifikasi prosedur}

Untuk memastikan bahwa prosedur yang dibuat telah sesuai dengan persyaratan dan kebutuhan, maka diperlukan proses verifikasi. Persyaratan dan kebutuhan yang dimaksud didasarkan pada control COBIT 5 untuk proses manage service request and incident. Verifikasi dilakukan dengan cara melakukan trace-back prosedur yang dibuat terhadap control-control tersebut. Trace-back dilakukan dengan memetakan setiap aktivitas umum pada prosedur pada control yang berkaitan. Hasil dari proses verifikasi menunjukkan bahwa aktivitas pada prosedur telah sesuai dengan control-control pada COBIT.

\subsection{Validasi prosedur}

Untuk memastikan bahwa prosedur yang dibuat dapat dipakai, maka perlu dilakukan validasi prosedur (Fauzi, 2012). Validasi dilakukan dengan melakukan simulasi pada proses manajemen insiden yang diwakili oleh diagram alur proses. Simulasi dilakukan dengan menggunakan tools Bizagi modeler dan dijalankan pada bagian process validation.

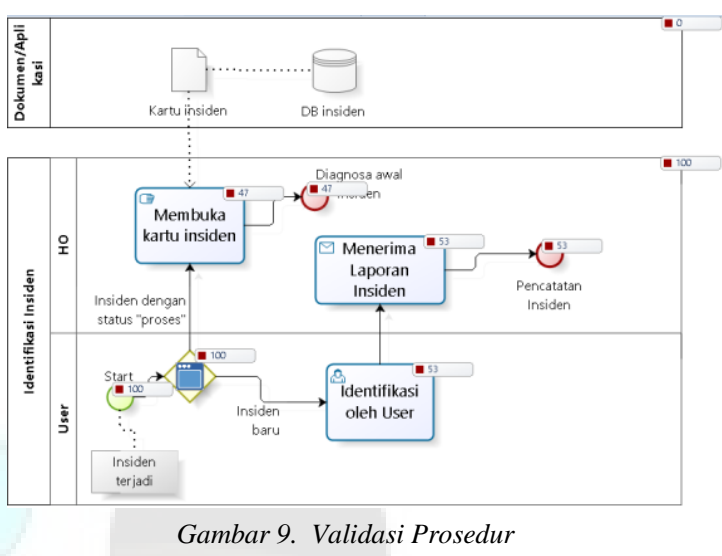

Skenario yang dipakai untuk setiap validasi proses adalah terdapat 100 inputan yang menggambarkan jumlah laporan insiden masuk yang akan ditangani. Validasi proses akan melihat bagaimana alur aktivitas dari penanganan insiden dan dari sejumlah insiden yang masuk akan terlihat presentase insiden yang menuju ke proses lain yang terkait.

Selain untuk validasi proses, simulasi juga dapat dilakukan untuk melakukan analisis waktu dan sumberdaya yang terkait dengan proses yang diuji.

\section{KESIMPULAN DAN SARAN}

Berdasarkan hasil penelitian yang dilakukan, maka didapatkan beberapa kesimpulan yaitu :

1. Proses manajemen insiden pada RS PHC Surabaya melibatkan sistem aplikasi helpdesk sebagai channel pelaporan dan pencatatan insiden. Pembuatan prosedur manjaemen insiden untuk helpdesk RS PHC Surabaya dibuat berdasarkan prosedur standar ITIL v3 dan disesuaikan dengan control COBIT 5 sehingga menghasilkan 11 prosedur yang terdiri dari 9 prosedur dari ITIL serta 2 peosedur tambahan berdasarkan COBIT 5. Prosedur manajemen insiden yang dibuat melibatkan aktivitas manual yang dilakukan oleh staf dan aktivitas yang dilakukan oleh system aplikasi helpdesk secara otomatis. Masing-masing dari prosedur terdiri dari tujuan prosedur, ruang lingkup, indikator, rincian aktivitasm diagram RACI, dan diagram alur menggunakan Business Process Model and Notations (BPMN).

2. Peran dan fungsi dalam manajemen insiden sangat penting untuk menjamin bahwa 
prosedur yang dibuat dapat dijalankan dan diterapkan dengan baik, khususnya pada level pertama penanganan insiden yang merupakan titik pertama insiden ditangani. Pelaksana yang telibat dibagi menjadi 8 fungsi yaitu User/Pelapor (U),Incident Manager (IM), Helpdesk Operator (HO), Helpdesk Specialist (HS), Software Manager (SM), Network Manager (NM), Maintenance Manager (MM), dan Data Management Manager (DMM).

3. Prosedur yang dikembangkan berdasarkan framework ITIL v3 merupakan aktivitas yang dilakukan secara berkelanjutan dalam pelaksanaanya, sedangkan untuk pelaporan dan evaluasi penanganan dilaksanakan pada akhir dan awal periode waktu.

Adapun keterbatasan dan saran yang dapat penulis berikan untuk penelitian selanjutnya adalah :

1. Penelitian ini hanya menggunakan control COBIT sebagai best practice tata kelola TI untuk verifikasi. Tahap verifikasi prosedur dapat mengaitkan dengan standar lain seperti ISO atau standar manajemen mutu untuk memastikan bahwa prosedur yang dibuat telah sesuai dengan kebutuhan yang ada.

2. Penelitian ini hanya melakukan pengujian dengan simulasi menggunakan tools bizagi. Untuk penelitian selanjutnya dapat dilakukan pengujian langsung kepada organisasi sehingga dapat memberikan feedback secara langsung dan nyata.

3. Validasi proses pada prosedur manajemen insiden yag dibuat masih dilakukan secara terpisah untuk masing- masing proses prosedur. Penelitian selanjutnya dapat melakukan validasi proses secara kesatuan untuk seluruh proses manajemen insiden.

\section{DAFTAR RUJUKAN}

Addy, R., 2007. Effective IT Service Managemen : to ITIL and Beyond. New York: Springer.

Ahmad, N. \& Shamsudin, Z. M., 2013. Systematic Approach to Successful Implementation of ITIL. Procedia Computer Science, pp. 237 - 244.

Bizagi, 2014. Bizagi Process Modeler User Guide, s.l.: Bizagi.

BSNI, 2008. SNI Sistem Manajemen Mutu Dasar-dasar dan Kosakata. Jakarta: s.n.

Buchsein, R. \& Dettmer, K., 2008. ISO/IEC
20000 - IT Service Management : Benefits and Requirements for Service Providers, s.1.: iETSolution.

Fauzi, A., 2012. Pembuatan Panduan Tata Laksana Manajemen Insiden Dengan Framework IT Infrastructure Library Studi Kasus :UPT. Puskom Polinema, Surabaya: ITS.

ISACA, 2012. COBIT 5 : Enabling Processes. s.1.:ISACA.

ITILv3, 2011. ITIL Version 3 : Service Operation. Buckinghamshire: OGC.

itSMF International, 2007. Foundations of IT Service Management Based on ITIL V3. Zaltbommel: Van Haren Publishing.

Silitonga, T. P. \& Ali, A. H. N., 2010. Sistem Manajemen Insiden Pada Program Manajemen Helpdesk dan Dukungan TI Berdasarkan Framework ITIL v3 (Studi Kasus Pada Biro Teknologi Informasi BPK$R I)$, Surabaya: ITS.

Simpson, R. C., 2004. An XML Representation for Crew Procedures, Johnson: NASA Faculty Fellowship Program.

Wallace, M. \& Webber, L., 2014. IT Governance : Policies \& Procedure. s.1.:Wolters Kluwer Law \& Business. 